\title{
A base de dados ISI e seu processo de seleção de revistas $^{*}$
}

James Testa

\section{Resumo}

Descreve o processo de seleção de revistas científicas adotado pelo Institute for

Scientific Information (ISI) para incorporar publicações em sua base de dados, abordando critérios como periodicidade, conteúdo editorial, internacionalidade e análise de citação.

\section{Palavras-chave}

Institute for Scientific Information (ISI); Avaliação de periódicos científicos.
A missão básica do Institute for Scientific Information (ISI), como uma companhia publicadora de bases de dados, é oferecer uma cobertura abrangente da mais importante e influente pesquisa realizada em todo o mundo. Atualmente, a base de dados ISI compreende mais de 16 mil títulos de revistas, livros e anais de congressos internacionais nas áreas de ciências, ciências sociais, artes e humanidades.

Uma parte importante dessa base são os 8 mil títulos de revistas internacionais que o ISI indexa anualmente, registrando os dados bibliográficos completos para cada documento incorporado, incluindo os resumos originais em inglês, os endereços dos autores e editores e as referências bibliográficas citadas em cada revista.

O compromisso do ISI é oferecer uma cobertura ampla das mais importantes e influentes revistas publicadas em todo o mundo para manter seus assinantes atualizados, suprindo suas necessidades de informação corrente e retrospectiva. Entretanto, abrangente não significa necessariamente incluir tudo (Garfield').

\footnotetext{
* Copyright (C) 1997, 1998 Institute for Scientific Information $\AA$. Trabalho originalmente publicado pelo ISI em formato eletrônico (URL: http:// www.isinet.com) e apresentado no Seminário sobre Avaliação da Produção Científica, realizado em São Paulo pelo Projeto SciELO, de 4 a 6 de março de 1998. Traduzido e publicado na Ciência da Informação com a permissão do autor.
}

\section{Por que selecionar?}

Pode parecer que, para ser abrangente, um índice da literatura científica publicada em revistas deva incluir todos os periódicos científicos que são publicados. Essa visão seria não somente impraticável economicamente, como também desnecessária, como têm demonstrado análises da literatura científica. Tem sido demonstrado que um número relativamente pequeno de revistas publica a maioria dos resultados significativos da pesquisa científica. Esse princípio é freqüentemente citado como Lei de Bradford (Garfield ${ }^{2}$ ). Na metade da década de 50, S. C. Bradford percebeu que o núcleo principal da literatura, em qualquer disciplina científica, era composto por menos de mil periódicos. Destes, relativamente poucos títulos têm grande relevância para um determinado assunto, enquanto muitos outros têm relevância menor. Contudo, os títulos com relevância menor para uma determinada disciplina ou assunto, caracteristicamente, têm grande relevância para outra disciplina. Assim, o núcleo da literatura científica pode formar-se em torno de vários assuntos, com revistas específicas tornando-se mais ou menos relevantes, dependendo do assunto. Bradford compreendeu que um núcleo essencial de revistas forma a base da literatura para todas as disciplinas e que, portanto, a maioria dos trabalhos importantes é publicada em relativamente poucas revistas $\left(G^{2}\right.$ rfield $\left.{ }^{2}\right)$. Análises de citação recentes demonstram que o pequeno número de 150 revistas responde por metade do que é citado e por $25 \%$ do que é publicado. Também tem sido demonstrado que um núcleo de aproximadamente 2 mil revistas abrange atualmente $85 \%$ dos artigos publicados e 95\% dos artigos citados (Garfield 3 ). Entretanto, esse núcleo não é estático. Sua conformação básica muda constan- 
temente. A missão da equipe editorial do ISI é identificar e avaliar novas e promissoras revistas que poderão ser de interesse para os assinantes do Instituto, como também excluir os títulos que se tornaram menos úteis.

\section{O processo de avaliação}

A avaliação e a seleção, tanto das revistas incluídas na base de dados como dos títulos excluídos, são realizadas continuamente pelo ISI a cada duas semanas. A equipe editorial do Instituto analisa cerca de 2 mil títulos novos de revistas anualmente, mas apenas $10 \%$ - $12 \%$ são selecionadas. Além disso, a cobertura de títulos existente nos produtos do ISI também passa por constante revisão. As revistas atualmente indexadas são monitoradas para assegurar que elas estão mantendo altos padrões e uma clara relevância para os produtos do ISI nos quais são repertoriadas.

Cada revista é submetida a um processo amplo de avaliação antes de ser selecionada ou rejeitada. Os editores do ISI que conduzem as avaliações das revistas possuem formação educacional apropriada às suas áreas de responsabilidade, assim como experiência e instrução em ciência da informação. Seu conhecimento da literatura de seus campos de especialização é ampliado por meio de consulta a redes instituídas de assessores que participam do processo de avaliação quando necessário.

Na avaliação das revistas, muitos fatores qualitativos e quantitativos são levados em consideração. Os padrões básicos de apresentação, o conteúdo editorial, a internacionalidade dos autores e a citação de dados associada a esses autores são analisados. Nenhum fator é considerado de forma isolada, mas, ao contrário, combinando e interrelacionando os dados, o editor é capaz de determinar os pontos fortes e fracos de uma revista na sua totalidade.

\section{Padrões básicos para revistas}

A periodicidade regular de publicação é um dos critérios mais elementares no processo de avaliação, e é de importância fundamental. Uma revista deve ser publicada de acordo com a freqüência especificada para ser considerada para inclusão na base de dados ISI. A habilidade de publicar pontualmente uma revista implica um substancial estoque de manuscritos indispensável para a sua viabilidade ininterrupta. Não é aceitável para uma revista aparecer cronicamente atrasada, semanas ou meses depois da data de sua abrangência (Garfield ${ }^{1}$ ). Para medir a periodicidade adequadamente, uma decisão sobre a abrangência jamais pode ser baseada em apenas um fascículo; geralmente, o editor precisa analisar pelo menos três exemplares diferentes.

ISI também observa se a revista segue ou não convenções editoriais internacionais, que otimizam a recuperação dos artigos originais. Essas convenções incluem títulos de revistas comunicativos, títulos de artigos e resumos inteiramente descritivos, dados bibliográficos completos em todas as referências citadas e endereço completo para cada autor.

Títulos dos artigos em inglês, resumos e palavras-chave são essenciais. Referências citadas na língua inglesa também são recomendadas. Embora informações científicas importantes sejam publicadas em todas as línguas, os autores devem providenciar a tradução para o inglês dos títulos de artigos, palavraschave e resumos, se desejam alcançar o maior público possível. Além disso, por seu aspecto puramente prático, não seria viável para o ISI assumir a responsabilidade de traduzir esse material.

A aplicação do processo de revisão por pares é outro indicador dos padrões de uma revista e evidencia a qualidade global da pesquisa que é apresentada e a exatidão e completeza das citações (Garfield ${ }^{1}$ ).

\section{Conteúdo editorial}

O verdadeiro núcleo da literatura científica está compreendido em um pequeno número de revistas. Entretanto, a pesquisa científica continua a dar origem a campos de estudo especializados, e novas revistas emergem assim que os resultados de pesquisa publicados sobre um novo assunto atingem massa crítica. O editor do ISI determina se o conteúdo de uma nova revista irá enriquecer a base de dados ou se o assunto já é adequadamente coberto.
O enorme volume de dados ao seu alcance e sua observação diária de virtualmente todas as novas revistas publicadas capacitam a equipe editorial do ISI a identificar assuntos emergentes e as "áreas quentes" na literatura.

\section{Internacionalidade}

A representação geográfica de uma revista é outra consideração. Para suprir as necessidades da sua base de assinantes internacionais, o ISI procura indexar revistas com diversidade internacional entre autores, tanto dos artigos originais como dos artigos citados.

Para refletir apropriadamente o contexto global no qual a pesquisa científica se desenvolve e para oferecer cobertura equilibrada em cada categoria, o Instituto procura também indexar as melhores revistas regionais. Contudo, em vez de comparar uma revista regional com todas as outras revistas de sua categoria específica, o editor do ISI a considera em termos das publicações provenientes da mesma área geográfica. Elevados padrões de apresentação e publicação, especialmente a periodicidade, e dados bibliográficos em inglês permanecem fatores essenciais para análise.

\section{Análise de citação}

O processo de avaliação do ISI é único, justamente porque seus editores têm uma riqueza de dados de citações à sua disposição. A importância de interpretar e compreender corretamente esses dados ao avaliar as revistas não pode ser enfatizada excessivamente. Em virtude de o número de autores e revistas variar enormemente entre as disciplinas, os níveis e as médias de citação em uma disciplina específica também variam grandemente. Áreas menores como botânica ou matemática não geram tantos artigos ou citações como ocorre com áreas maiores, neste caso, biotecnologia ou genética. Do mesmo modo, em algumas áreas, particularmente em artes e humanidades, pode levar relativamente muito tempo, até mesmo vários anos, para um artigo atrair um número significativo de citações, enquanto em outras áreas, como as ciências da vida, não é incomum as citações atingirem o topo somente após alguns anos. Essas ocorrências devem ser levadas em consideração para que os dados de citação sejam usados corretamente. 
Vários tipos de dados de citação são utilizados. Para revistas estabelecidas, os dados incluem medidas de citação completas, fator de impacto e índice de imediacidade ${ }^{* *}$. Para revistas recém-criadas, os editores examinam os registros das publicações dos autores e dos membros da comissão editorial, para saber onde seus artigos têm sido publicados e se seus trabalhos têm sido citados. Além disso, considerando que o ISI captura todas as referências citadas em cada uma das 8 mil revistas da sua base, os dados de citação estão disponíveis tanto sobre as revistas indexadas, como sobre as não indexadas, mas que foram citadas por um entre os 8 mil títulos do núcleo.

\section{Revistas eletrônicas}

Como dito antes, a missão básica do ISI é oferecer acesso às mais importantes e influentes revistas de todo o mundo. Esse compromisso se estende à avaliação e inclusão de revistas eletrônicas. Embora o meio eletrônico necessite de algumas alterações em seu processo de avaliação, o Instituto ainda busca analisar todos os indicadores de qualidade encontrados em revistas tradicionais. Conteúdo editorial, valor do corpo editorial e dos autores, auxílio financeiro recebido, revisão por pares e internacionalidade permanecem importantes como sempre.

\section{The ISI Database: the journal selection process}

\begin{abstract}
It describes the journal selection process of the Institute for Scientific Information (ISI) aiming at including scientific publications in its database. Some criteria are discussed such as timeliness, editorial content, internationality and citation analysis.
\end{abstract}

\section{Keywords}

Institute for Scientific Information (ISI); Scientific periodicals evaluation.

\footnotetext{
* * Por indicação de especialistas brasileiros, o termo técnico immediacy index foi traduzido para índice de imediacidade, que, embora não exista em português, expressa mais adequadamente o seu conceito: medida que indica o quão rapidamente um artigo é citado.
}

A periodicidade deve ser avaliada de uma forma diferente no caso do formato eletrônico. Revistas eletrônicas de pesquisa podem apresentar duas formas básicas - podem tanto ser publicadas no formato tradicional como "fascículos" contendo uma seleção de artigos, quanto publicar um artigo por vez. Este último formato é uma característica interessante das revistas eletrônicas, tornando possível disseminar informações cada vez mais rapidamente. Nesta etapa inicial da história da publicação de revistas eletrônicas, padrões definidos para periodicidade ainda estão sendo desenvolvidos. Um bom método para determinar a "saúde" de uma revista eletrônica é observar a regularidade com que os artigos são divulgados. É claro que o número de artigos divulgados dependerá da disciplina. Em geral, contudo, não esperaríamos transcorrer um período de seis meses sem alguma atividade.

Revistas com versões impressas freqüentemente desenvolvem edições eletrônicas. A versão eletrônica pode fornecer materiais suplementares e, muitas vezes, levarão a informação do editor ao pesquisador mais rapidamente. Se o formato eletrônico oferece esse tipo de mudanças positivas, então poderíamos considerar a sua indexação no lugar da versão impressa.

Em setembro de 1994, ISI aceitou sua primeira revista eletrônica, The Online Journal of Knowledge Synthesis for Nursing. Desde então, incorporamos outras 16. Nossos editores têm sido instruídos para identificar revistas eletrônicas relevantes, avaliando-as para uma possível cobertura. Esperamos que a nossa cobertura de revistas eletrônicas cresça firmemente.

\section{Como recomendar revistas}

O ISI está aberto para sugestões e recomendações de títulos para inclusão em sua base de dados. Regularmente, realizamos pesquisas de mercado e junto aos clientes. Para recomendar uma revista para avaliação, basta contatar o Editorial Development Department, através do fax 215-386-6362, ou pelo correio eletrônico journals@isinet.com, informando o título completo da revista, seu ISSN, nome e endereço completo do editor e do publicador. Se possível, enviar um exemplar do fascículo mais recente e, posteriormente, os dois ou três números seguintes tão logo forem publicados. Deve-se incluir, ainda, uma breve justificativa expondo as características únicas da revista e como ela se distingue de outras publicações em seu campo. Os exemplares dos fascículos da revista devem ser enviados para Publication Processing Department, ISI, 3501 Market Street, Philadelphia, PA 19104 USA.

\section{REFERÊNCIAS BIBLIOGRÁFICAS}

1. GARFIELD, E. How ISI selects journals for coverage: quantitative and qualitative considerations. Current Contents, May, 1990.

2. GARFIELD, E. Citation indexing. New York: John Wiley \& Sons, 1979.

3. GARFIELD, E. The significant scientific literature appears in a small core of journals. The Scientist, v. 10, n. 17, Sept. 1996. 